\title{
Germaine de Staël: forging a politics of mediation, sous la direction de Karyna Szmurlo
}

\section{Stéphanie Genand}

\section{(2) OpenEdition}

1 Journals

\section{Édition électronique}

URL : http://journals.openedition.org/studifrancesi/3779

DOI : 10.4000/studifrancesi.3779

ISSN : 2421-5856

Éditeur

Rosenberg \& Sellier

\section{Édition imprimée}

Date de publication : 1 décembre 2012

Pagination : 584-585

ISSN : 0039-2944

\section{Référence électronique}

Stéphanie Genand, « Germaine de Staël: forging a politics of mediation, sous la direction de Karyna Szmurlo », Studi Francesi [En ligne], 168 (LVI | III) | 2012, mis en ligne le 30 novembre 2015, consulté le 08 mars 2021. URL : http://journals.openedition.org/studifrancesi/3779 ; DOI : https://doi.org/ 10.4000/studifrancesi.3779

Ce document a été généré automatiquement le 8 mars 2021.

\section{(c)}

Studi Francesi è distribuita con Licenza Creative Commons Attribuzione - Non commerciale - Non opere derivate 4.0 Internazionale. 


\title{
Germaine de Staël: forging a politics of mediation, sous la direction de Karyna Szmurlo
}

\author{
Stéphanie Genand
}

\section{RÉFÉRENCE}

AA. VV., Germaine de Staël: forging a politics of mediation, sous la direction de Karyna SZMURLo, Oxford, Voltaire Foundation, SVEC, 2011, 12, pp. 311.

1 L'œuvre de Germaine de Staël, et il faut s'en réjouir, a toujours suscité de nombreux travaux outre-Atlantique. Les analyses pionnières de M. Gutwirth (Mme de Staël, Novelist: the Emergence of the Artist as Woman), qui inaugurèrent la piste des "études féminines», comme celles de K. Szmurlo consacrées à Corinne (The Novel's Seductions: Staël's Corinne in Critical Inquiry) ou plus récemment aux transferts culturels (G. de Staël: Crossing the Borders) ont régulièrement renouvelé les approches critiques. G. de Staël: forging a Politics of Mediation n'échappe pas à la règle: dirigé par K. Szmurlo, qui réunit ici 15 contributions issues pour la plupart d'un colloque organisé à Saint-Louis en 2009, l'ouvrage entend privilégier la dimension politique de G. de Staël. À rebours des lectures biographiques, dont M. Gutwirth souligne la récente atténuation au terme d'une longue «history of denigration», il s'agit de rééquilibrer le parcours de Staël en lui restituant son rôle d'activiste et de théoricienne du libéralisme. L'ambition est double, comme K. Szmurlo le rappelle dans son introduction: revaloriser l'importance historique d'un corpus trop souvent envisagé sous l'angle romanesque ou critique et souligner la résonance de Staël à notre époque. Cet objectif s'appuie sur le concept de «mediation». Issu de la sociologie anglo-saxonne et récemment mis en lumière par C. Siskin et W. Warner dans What is Enlightenment? (Chicago Press, 2010), il s'intéresse aux phénomènes de mise en relation. Idées, personnages, pays et modèles culturels entrent en contact les uns avec les autres par l'intermédiaire des discussions, des voyages et de la presse, pour ne citer que quelques instruments de ces échanges. Cette 
approche, qui met l'accent sur la circulation plus que sur les individus ou les textes singuliers, permet aux auteurs de What is Enlightenment? de lire le xvIII ${ }^{\mathrm{e}}$ siècle comme une étape cruciale de l'histoire de la «mediation». Des notions comme celles de «social network» ou de «transmission» nourrissent une réflexion sur les circuits de diffusion, les contacts avec l'étranger ou l'ouverture de textes désormais chargés d'influences ou susceptibles à leur tour d'en exercer. Appliquée au corpus staëlien, la «mediation» vise à souligner la dynamique et le cosmopolitisme d'une œuvre et d'un parcours exemplairement exocentrés.

2 Deux parties organisent cette lecture de Staël sous l'angle de l'intercession: la première, intitulée «Revolutionary Engagements», s'intéresse à ses activités historiques sur la scène publique: qu'elle tente d'infléchir l'opinion en publiant des Réflexions sur la paix intérieure ou qu'elle intervienne en personne pour libérer La Fayette, Staël joue un rôle effectif dans la politique du temps. À Versailles devant la Reine ou engagée en faveur de la cause abolitionniste, elle expose des convictions qui prolongent sa remise en cause $\mathrm{du}$ «caractère national». Les Considérations sur la Révolution française inaugurent dans cette perspective une historiographie libérale, soucieuse de rétablir la légitimité d'un combat pour la liberté confisqué par la Terreur et détourné de son objectif initial. Staël, comme le Groupe de Coppet et B. Constant plus particulièrement, promeut une pensée de la réconciliation contre les extrêmes et le machiavélisme moderne de Napoléon. La seconde partie, intitulée «In space and time: cultural cross-currents», met l'accent sur les lieux de la sociabilité staëlienne et le contact avec l'étranger: le château de Coppet, qui reçoit un nombre si important de visiteurs qu'il nourrit un «réseau» plus qu'un «groupe», favorise une connaissance affinée des pays du «Grand Tour». L'Italie, figée par le succès de Corinne en 1807 dans l'image d'une frivolité incompatible avec l'autonomie politique, inspire plusieurs relectures qui nuancent les positions staëliennes: qu'il s'agisse de rappeler l'œuvre contemporaine d'U. Foscolo, ignorée de Staël mais dont les Le ultime lettere de Jacopo Ortis déclenchent une vague d'italomanie en Angleterre, ou de retracer la généalogie littéraire de l'improvisatrice, les voyages invitent à distinguer le réel du stéréotype dans Corinne. Cette volonté de rencontre se retrouve dans De l'Allemagne: l'historiographie d'Herder veille à restituer le passé sans lui superposer distance ni jugement. Trouver la langue la plus à même de donner vie au monde antique, tel est l'un des enjeux pour cet ouvrage structuré par la pensée de l'autre. La publication à Londres en 1813, alors que la presse britannique choisit de signaler les passages censurés par la police de Bonaparte, restitue à De l'Allemagne son ambition politique: rappeler l'idéal des Lumières et l'importance du combat pour la liberté.

Germaine de Staël: forging a politics of mediation réussit, au terme d'un parcours dense et varié, à réorienter la lecture de ce corpus. Longtemps occultée par la sensibilité, ellemême support d'une féminité synonyme d'hystérie, l'œuvre staëlienne révèle l'importance de son implication politique. Cet angle souffre cependant de l'ambiguïté du concept de «mediation»: s'il vise à valoriser l'influence de Staël sur les événements et les opinions, il conduit quelquefois à séparer artificiellement les faits des textes. La salonnière active du Directoire, et dont les amitiés rayonnent à travers l'Europe, jouxte la théoricienne du libéralisme et l'opposante exilée. Ce manque de clarté, d'autant plus préjudiciable qu'il s'agit de tourner légitimement la page du «biographical turn», privilégie les actions sur les œuvres: les démarches diplomatiques, les correspondances, les déplacements et les rencontres organisés par Staël nourrissent incontestablement 
sa pensée. Mais cet axe historique requiert peut-être une explicitation du corpus mobilisé et des instruments qui sous-tendent ce retour à l'auteur: s'oriente-t-on vers la biographie politique? La correspondance a-t-elle le même statut que les Considérations sur la Révolution française ou que Corinne ou l'Italie? Ces réserves, auxquelles s'ajoutent quelques anachronismes inévitables dans toute lecture «actualisante»-parler de «social network» pour Coppet peut surprendre, malgré l'importance de ce concept dans la sociologie anglo-saxonne -, n'effacent pas le réel intérêt de l'ouvrage: donner à réfléchir en montrant la complexité du parcours staëlien. 